\title{
Component Alignment in Total knee Replacement
}

\author{
Raviprasad Kattimani* \\ Specialty Doctor in Trauma and Orthopaedics, Warwick hospital, UK
}

Submission: March 27, 2018; Published: April 25, 2018

*Corresponding author: Raviprasad Kattimani, Specialty Doctor in Trauma and Orthopaedics, Warwick hospital, Lakin road, Warwick, CV34 5BW, UK, Email: raviprasad.kattimani@gmail.com

\section{Introduction}

Total knee replacement (TKR) is one of the most commonly performed surgical intervention providing substantial relief from pain and improvement in functional disability in patients with knee arthritis [1]. Although the survival of primary TKR s is excellent with $95 \%$ of survival at 10 years for most implants [2], approximately $20 \%$ of those who undergo TKR are not satisfied with the outcome at the end of one year assessment [3]. Restoration of knee alignment is one of the main determinants of successful outcomes after TKR [4]. Implant malalignment following primary TKA has been reported to be the primary reason for revision in 7\% of revised TKR [5].

\section{Discussion}

\section{Alignment axes}

Vertical Axis is defined as a vertical line that extends distally from the center of the pubic symphysis on a normal weight bearing antero posterior radiograph. This vertical axis is used as a reference axis/line from which the other axes are determined [5].

The mechanical axis of the lower extremity is determined by drawing a line from the centre of the femoral head to the centre of the ankle joint, which corresponds to an approximately $3^{\circ}$ slope compared with that of the vertical axis. The anatomic axis of the lower extremity is an axis in relation to the intra medullary canals. The femur anatomical axis (FAA) is determined by a line drawn proximal to distal in the intra medullary canal bisecting the femur in one-half. Tibia anatomical axis (TAA) is created by a line drawn proximal to distal in the intra medullary canal bisecting the tibial in half [4].

On antero posterior evaluation, the anatomic axis and mechanical axis of femur has $5^{\circ}$ to $7^{\circ}$ of inclination difference between them, however anatomic and mechanical axis of the tibia correspond with each other (Figure 1). Hip knee axis (HKA) also known as mechanical axis of lower limb is commonly defined as the angle between the mechanical axis of the femur and the mechanical axis of the tibia [6].

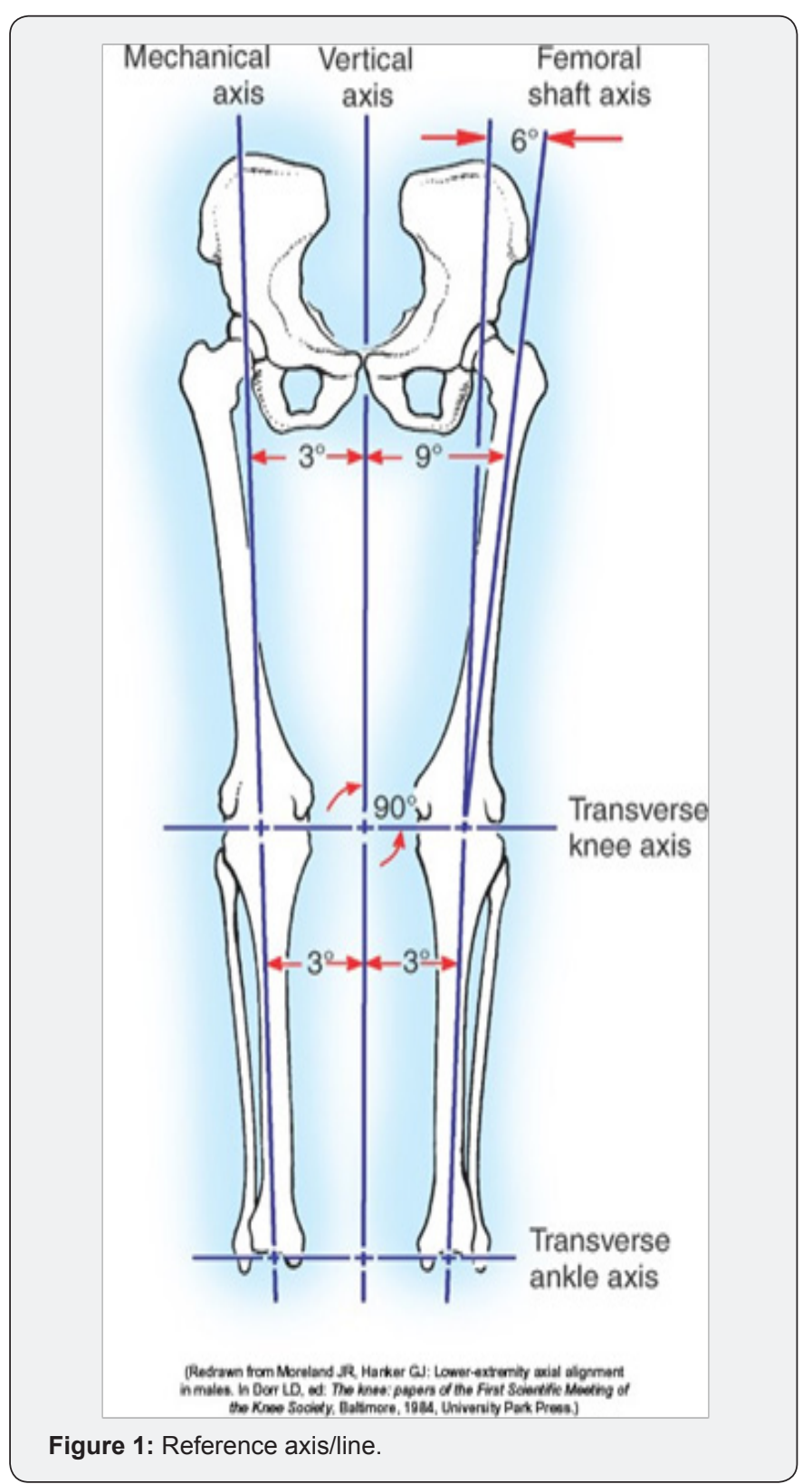




\section{Coronal alignment}

One of the goals of TKR is restoration of overall mechanical axis of the lower limb also known as HKA angle. Tibiofemoral axis (TFA) can be determined on short anteroposterior radiographs of the knee when full length weight bearing views are not available. The acceptable alignment is between $7^{\circ}$ and $9^{\circ}$ of valgus. (7). According to Fang et al increased failure rates were noted in TKR with varus malalignment $\left(\mathrm{TFA}<2.5^{\circ}\right)$ and valgus malalignment $\left(\mathrm{TFA}>7.5^{\circ}\right)$ [7]. It was found that knee aligned $+/-3^{\circ}$ of neutral mechanical axis had better international knee society scores (KSS) and short form 12 (SF 12) scores at 6 weeks, 3 months, 6 months, and 12 months after surgery [8].

The optimal distal femoral cut is made at $2^{\circ}-7^{\circ}$ of valgus to the FAA to achieve optimal mechanical alignment. Femoral component placement $>8^{\circ}$ of valgus in relation to FAA has resulted in 5 time's higher rates of failure. [9]. Coronal alignment of femoral component $>8^{\circ}$ and $<2^{\circ}$ of valgus with respect to the FMA were associated with implant failure [10]. The tibia component should be placed at neutral alignment $\left(90^{\circ}\right)$ in coronal plane with maximum bone coverage and this is achieved by proximal tibial cut at $90^{\circ}$ to the mechanical axis of tibia $[9,11]$. Tibial component $>30$ of varus had increased risk of medial bone collapse [12]. According to Kim et al. [11]. No knees in the neutrally aligned group required revision of the components, and $3.4 \%$ of the varus malaligned tibia component required revision at 15.8 years of average follow up.

\section{Sagittal Alignment}

The ideal femoral component positioning in sagittal plane is considered to be 0-3 degrees of flexion [10]. Hyperextension of the femoral component apparently increases the risk of osteolysis [13] and also it may create a notch in the anterior femoral cortex, which can increase the potential risk of a supracondylar fracture [14]. The study by Lustig et al. [15] in 95 patients found that Sagittal alignment of femoral component greater than $3.5^{\circ}$ from the mechanical axis was found to increase the relative risk of mild flexion contracture at one-year follow-up by 2.9 times.

The desired tibial sagittal alignment for most prosthesis types is a posterior slope between $0^{\circ}$ to $7^{\circ}$ [10]. Tibial malalignment in the sagittal plane $\left(<0^{\circ}\right.$ or $\left.>7^{\circ}\right)$ had a failure rate of $4.5 \%$, as compared to a failure rate of $0.2 \%$ in the neutrally aligned group [11]. In sagittal alignment the proximal tibia should never resected be in an anterior slope, as it would lead to impaired posterior flexion space and possible instability [16].

\section{Rotational Alignment}

There are many anatomical landmarks used to determine rotational alignment for femur. The trans epicondylar axis (TEA) of the femur is regarded as the gold standard axis for establishing the rotational alignment of the femoral component during TKR $[8,17,18]$, other methods are trans-sulcus axis (TSA) also known as Whiteside's line [19], gap balancing (GB) and posterior condylar axis (PCA). Femoral component should not be implanted in internal rotation with respect to TEA as the femoral component should be placed in $2-5^{\circ}$ of external rotation in relation to TEA $[11,20]$.

It is accepted that placement of femoral component in approximately $3^{\circ}$ to $5^{\circ}$ of external rotation, relative to the posterior condylar axis, improves patellar tracking. Externally rotating the femur $3-4^{\circ}$ may be accurate with most patients; however in valgus knee with hypoplastic lateral femoral condyles every $1 \mathrm{~mm}$ of asymmetrical cartilage erosion can change the femoral rotation by approximately $1^{\circ}$ if rotational alignment is guided by PCA [20]. Femoral component in excessive external rotation increases the medial flexion gap and may lead to symptomatic flexion instability; external rotation of this component by as little as $5^{\circ}$ from the TEA increases shear forces on the patellar component $[17,18]$. Bell et al. [20] reported internal rotation of femoral component $\left(>3^{\circ}\right.$ internal rotation in relation to TEA) was one of the significant etiological factors for pain after TKR. (24) Femoral component in flexion creates lift off of the anterior flange and patellar impingement and excessive extension of the femoral implant will displace the extensor mechanism anteriorly, increasing retinacular tension and patella femoral compressive force [21].

There are many anatomical landmarks used for the tibial component placement for rotational alignment which includes medial border of the tibial tubercle axis (TTA) $[22,23]$, transverse axis of the tibia, medial $1 / 3$ of the tibial tubercle $[22,24]$ and malleolar axis [23]. There is no gold standard landmark for rotational alignment of the tibial component. Relying only on the TTA has been associated with mal positioning of tibial component [25] so combination of reference points may reduce errors in component position [17]. Tibial component malrotation is more common and typically more severe than femoral component malrotation [26]. It was found that internal rotation of tibia component $>9^{\circ}$ in relation to TTA caused pain and functional deficit but there was no pain in patient with external rotational errors [18] and similar results were found by Bell et al. [20].

\section{Conclusion}

The goal of successful TKR is to achieve accurate alignment of components. Malaligned components may lead to pain, poor functional outcome and impair stability of the joint [20,26-29]. The acceptable parameters for accurate alignment are knee aligned $+/-3^{\circ}$ of neutral mechanical axis [8] Coronal alignment of femoral component $>8^{\circ}$ and $<2^{\circ}$ of valgus with respect to the FMA [10]. The tibia component should be placed at neutral alignment $\left(90^{\circ}\right)$ in coronal plane with maximum bone coverage $[9,11]$. The ideal femoral component positioning in sagittal plane is considered to be $0-3$ degrees of flexion and the desired tibial sagittal alignment for most prosthesis types is a posterior slope between $0^{\circ}$ to $7^{\circ}[10]$. Femoral component should not be implanted in internal rotation with respect to TEA 
as the femoral component should be placed in $2-5^{\circ}$ of external rotation in relation to TEA $[11,20]$. There is no gold standard for measurement of tibial component rotation Excessive internal rotation of tibia component when measured in relation to the tibial tubercle can lead to knee pain [10].

\section{References}

1. Ethgen 0 , Bruyère 0 , Richy $F$, Dardennes $C$, Reginster JY (2004) Health-related quality of life in total hip and total knee arthroplasty. A qualitative and systematic review of the literature J Bone Joint Surg Am 86-A(5): 963-974.

2. Graves S, Davidson D, de Steiger RN (2013) Australian Orthopaedic Association National Joint Replacement Registry Annual Report.

3. Bourne RB, Chesworth BM, Davis AM, Mahomed NN, Charron K DJ (2010) Patient satisfaction after total knee arthroplasty: who is satisfied and who is not? Clin Orthop 468(1): 57-63.

4. Luo CF (2004) Reference axes for reconstruction of the knee. Knee 11(4): 251-257.

5. Schroer WC, Berend KR, Lombardi AV, Barnes CL, Bolognesi MP, et al. (2013) Why are total knees failing today? Etiology of total knee revision in 2010. J Arthroplasty 28(8): 116-119.

6. Cooke TDV, Sled EA, Scudamore RA (2007) Frontal plane knee alignment: a call for standardized measurement. J Rheumatol 34(9): 1796-1801.

7. Fang DM, Ritter MA, Davis KE (2009) Coronal alignment in total knee arthroplasty. J Arthroplasty 24(6): 39-43.

8. Churchill DL, Incavo SJ, Johnson CC, Beynnon BD (1998) The transepicondylar axis approximates the optimal flexion axis of the knee. Clin Orthop Relat Res 356: 111-118.

9. Ritter MA, Davis KE, Meding JB, Pierson JL, Berend ME, et al. (2011) The effect of alignment and BMI on failure of total knee replacement. J Bone Joint Surg (Am) 93(17): 1588-1596.

10. Kirill Gromov, Mounim Korchi, Morten G Thomsen, Henrik Husted, Anders Troelsen (2014) What is the optimal alignment of the tibial and femoral components in knee arthroplasty? An overview of the literature Acta Orthop 85(5): 480-487.

11. Kim YH, Park JW, Kim JS, Park SD (2014) The relationship between the survival of total knee arthroplasty and postoperative coronal, sagittal and rotational alignment of knee prosthesis. Int Orthop 38 (2): 379 385.

12. Berend ME, Ritter MA, Meding JB, Faris PM, Keating EM, et al. (2004) Tibial component failure mechanisms in total knee arthroplasty. Clin Orthop 428: 26-34.

13. Dennis DA (2004) Evaluation of painful total knee arthroplasty. J Arthroplasty 19: 35-40.

14. Li G, Papannagari R, Most E, Park SE, Johnson T, et al. (2005) Anterior tibial post impingement in a posterior stabilized total knee arthroplasty. J Orthop Res 23(3): 536-541.
15. Lustig S, Scholes CJ, Stegeman TJ, Oussedik S, Coolican MRJ, et al (2012) Sagittal placement of the femoral component in total knee arthroplasty predicts knee flexion contracture at one-year follow-up. Int Orthop 36(9): 1835-1839.

16. Waelchli B, Romero J (2001) Dislocation of the polyethylene inlay due to anterior tibial slope in revision total knee arthroplasty. Knee Surg Sports Traumatol Arthrosc 9(5): 296-298.

17. Miller MC, Berger RA, Petrella AJ, Karmas A, Rubash HE (2001) Optimizing femoral component rotation in total knee arthroplasty. Clin Orthop Relat Res 392: 38-45.

18. Olcott CW, Scott RD (1999) The Ranawat Award: Femoral component rotation during total knee arthroplasty. Clin Orthop Relat Res 367: 3942.

19. Arima J, Whiteside LA, McCarthy DS, White SE (1995) Femoral rotational alignment, based on the anteroposterior axis, in total knee arthroplasty in a valgus knee. A technical note. J Bone Joint Surg (Am) 77(9): 1331-1334.

20. Bell SW, Young P, Drury C, Smith J, Anthony I, et al. (2014) Component rotational alignment in unexplained painful primary total knee arthroplasty. Knee 21(1): 272-277.

21. Insall JN (2006) Surgical techniques and instrumentation in total knee arthroplasty. In: Scott WN (Edt.), Insall \& Scott's surgery of the knee ( $4^{\text {th }}$ edn), Churchill Livingstone; Elsevier, Philadelphia, USA, pp. 739804.

22. Dalury DF (2001) Observations of the proximal tibia in total knee arthroplasty. Clin Orthop Relat Res 389: 150-155.

23. Eckhoff DG, Metzger RG, Vandewalle MV (1995) Malrotation associated with implant alignment technique in total knee arthroplasty. Clin Orthop Relat Res 321: 28-31.

24. Graw BP, Harris AH, Tripuraneni KR, Giori NJ (2010) Rotational references for total knee arthroplasty tibial components change with level of resection. Clin Orthop Relat Res 468(10): 2734-2738.

25. Bonnin MP, Saffarini M, Mercier PE, Laurent JR, Carrillon Y (2011) Is the anterior tibial tuberosity a reliable rotational landmark for the tibial component in total knee arthroplasty? J Arthroplasty 26(2): 260267.

26. RL Barrack, T Schrader, AJ Bertot, MW Wolfe, L Myers (2001) Component rotation and anterior knee pain after total knee arthroplasty. Clin Orthop Relat Res 392: 46-55.

27. Bong MR, Di Cesare PE (2004) Stiffness after total knee arthroplasty. J Am Acad Orthop Surg 12(3): 164-171.

28. Page SR, Deakin AH, Payne AP, Picard F (2011) Reliability of frames of reference used for tibial component rotation in total knee arthroplasty . Comput Aided Surg 16(2): 86-92.

29. Nicoll D, Rowley DI (2010) Internal rotational error of the tibial component is a major cause of pain after total knee replacement J Bone Joint Surg (Br) 92(9): 1238-1244. 


\section{Your next submission with Juniper Publishers} will reach you the below assets

- Quality Editorial service

- Swift Peer Review

- Reprints availability

- E-prints Service

- Manuscript Podcast for convenient understanding

- Global attainment for your research

- Manuscript accessibility in different formats

( Pdf, E-pub, Full Text, Audio)

- Unceasing customer service

Track the below URL for one-step submission https://juniperpublishers.com/online-submission.php 